\title{
Reliability and convergent validity of the past-week Modifiable Activity Questionnaire
}

\author{
Kelley Pettee Gabriel ${ }^{1, *}$, James J McClain ${ }^{2}$, Kendra K Schmid ${ }^{3}$, Kristi L Storti ${ }^{4}$ and \\ Barbara E Ainsworth ${ }^{5}$ \\ 'Division of Epidemiology, Human Genetics and Environmental Sciences, University of Texas School of Public \\ Health, Austin Regional Campus, University of Texas Administration Building (UTA), 1616 Guadalupe \\ Street - Suite 6.338, Austin, TX 78701, USA: ${ }^{2}$ Cancer Prevention Fellowship Program, National Cancer \\ Institute, Bethesda, MD, USA: ${ }^{3}$ Department of Biostatistics, University of Nebraska Medical Center, Omaha, \\ NE, USA: ${ }^{4}$ Department of Epidemiology, University of Pittsburgh, Pittsburgh, PA, USA: ${ }^{5}$ Healthy Lifestyles \\ Research Center, Program in Exercise and Wellness, Arizona State University, Mesa, AZ, USA
}

Submitted 27 January 2010: Accepted 10 August 2010: First published online 15 September 2010

\begin{abstract}
Objective: To examine the reliability and convergent validity of physical activity (PA) and inactivity estimates obtained with the past-week Modifiable Activity Questionnaire (PWMAQ).

Design: The PWMAQ, an interviewer-administered questionnaire, was administered twice, one week apart, during visits 3 and 4 of six total visits. Intra-class correlation coefficients (ICC) between administrations of the PWMAQ were used to assess the reliability of summary estimates. Spearman rank-order correlation coefficients $(\rho)$ were used to examine the associations of PWMAQ summary estimates with temporally matched and averaged accelerometer data in all participants and then stratified by whether the data were reflective of usual PA. Setting: Data were obtained from the Evaluation of Physical Activity Measures in Middle-Aged Women (PAW) study.

Subjects: Sixty-six women, mean age $52 \cdot 6$ (SD 5.4) years.

Results: The reliability of the PWMAQ physical inactivity estimate suggested substantial agreement over one week (ICC $=0 \cdot 77,95 \%$ CI $0 \cdot 57,0 \cdot 82 ; P<0 \cdot 0001$ ). With the exception of light-intensity PA, the PWMAQ leisure PA estimate was significantly associated with averaged accelerometer data $(\rho=0 \cdot 33-0 \cdot 76$; $P<0 \cdot 05$ ). For both temporally matched and averaged accelerometer data, correlation coefficients were higher between the PWMAQ estimate and moderatewalk- to vigorous-intensity PA in those who indicated that reported activity was reflective of usual PA; however, the association with moderate-lifestyle-intensity PA was higher in those reporting that data were not reflective.

Conclusions: The PWMAQ is a reliable and valid measure of leisure PA levels in middle-aged women and supports subsequent studies evaluating this questionnaire in other population subgroups.
\end{abstract}

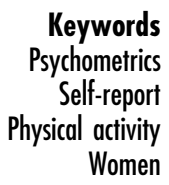

Keywords

Selfometrics

Physical activity

Women
For decades, researchers have been interested in detecting and quantifying physical activity-related energy expenditure in order to examine the relationship between physical activity and health-related outcomes. If researchers are interested in measuring movement, rather than physical activity behaviour, then objective activity monitors (i.e. accelerometers) are optimal. However, objective measures may not be appropriate for all research applications due to the lack of contextual information (i.e. activity type) that they provide. Thus, subjective measures are still needed to estimate participants' physical activity levels in settings where objective methods may not provide meaningful information to appropriately address study objectives.
Self-report measures of physical activity have their own set of limitations, however, that can undermine the precision of the derived estimate (e.g. recall bias, language and educational barriers). Further, the overall quality of many commonly used physical activity questionnaires, including the reproducibility and validity of computed summary estimates (i.e. MET·h/week), is often not well understood in middle-aged women. Furthermore, most questionnaires used in epidemiological studies of middleaged women have not been evaluated against objective measures of physical activity ${ }^{(1)}$. Limited agreement between a questionnaire and a direct measure of physical activity may influence the interpretation of the findings in any 
situation where physical activity is used as an outcome, exposure or confounding variable ${ }^{(2)}$. The lack of accurate physical activity measures used across studies could lead to inconclusive associations between physical activity and health-related outcomes of interest.

The Modifiable Activity Questionnaire (MAQ) was originally developed by Kriska et al. ${ }^{(3)}$ to assess physical activity in American Indian populations and used one form to assess historical leisure physical activity, current (past-year and past-week) leisure and occupational physical activity, and physical inactivity levels. The MAQ was designed for easy modification of included activities to maximize its use in a variety of populations ${ }^{(4)}$. When examining the psychometric properties of the past-week component in Pima American Indians, correlation coefficients $(\rho)$ ranged from $0 \cdot 35$ to $0 \cdot 77^{(3)}$. Kriska et al. ${ }^{(3)}$ also examined the validity of the past-week MAQ leisure physical activity estimate against the Caltrac activity monitor (average counts/h) with walking included and excluded from the summary estimate, and showed moderate to high validity $(\rho=0.80$ and 0.62 , respectively; both $P<0 \cdot 05$ ).

Since the initial evaluation of the $\mathrm{MAQ}^{(3)}$, the past-year component of the MAQ has been widely used in epidemiological studies ${ }^{(5-8)}$, including the Woman On the Move through Activity and Nutrition (WOMAN) study, a clinical trial of early postmenopausal women ${ }^{(5,9-11)}$. However, physical activity questionnaires that utilize a longer time frame may be limited by inaccurate participant recall ${ }^{(12)}$ and poor temporal relationship between one's past-year physical activity and current physical activity status $^{(13)}$. A stand-alone version of the past-week MAQ (PWMAQ) was developed for the WOMAN study to provide a supplemental measure of current leisure physical activity levels intended to track adherence to physical activity goals. The global reliability and validity results of the PWMAQ leisure physical activity estimate have been reported previously ${ }^{(1)}$. The purpose of the current study was to extend upon the earlier results to evaluate the one-week test-retest reliability of the physical inactivity estimate and in addition give a comparison of leisure physical activity estimates with accelerometer data averaged over 5 weeks in middle-aged women. The relationship between the PWMAQ leisure physical activity estimate and bouts of moderate- to vigorousintensity physical activity (MVPA) and vigorous-intensity physical activity, and the utility of an additional question relating to whether reported activity was reflective of usual physical activity levels, were also examined.

\section{Experimental methods}

The evaluation of the PWMAQ was conducted within the larger Evaluation of Physical Activity Measures in MiddleAged Women (PAW) study. The PAW study was designed to evaluate the psychometric properties of six physical activity measures (i.e. five questionnaires and a walkingbased performance measure) used in epidemiological studies of physical activity and health. The protocol used in the PAW study has been reported previously ${ }^{(1,14)}$. All participants provided written informed consent, and the study protocol was approved by the institutional review board at Arizona State University. Participants completed six consecutive weekly visits from August 2007 to May 2008, each lasting 30-60 min. Seventy-seven women were screened, and sixty-six ( $85 \cdot 7 \%)$ enrolled into the study. Among those who were not enrolled ( $n$ 11), reasons included lack of time ( $n$ 9), family obligations ( $n$ 1) and pre-existing health condition $(n 1)$ that precluded participation in the study.

\section{Past-week Modifiable Activity Questionnaire}

The PWMAQ is an interviewer-administered survey that assesses leisure physical activities over the past $7 \mathrm{~d}$ (i.e. week), time spent watching television (TV) and nonoccupational computer use, and extreme levels of inactivity due to disability. The structure of the PWMAQ is similar to the past-year version of the $\mathrm{MAQ}^{(3)}$; however, the occupation and transportation sections are omitted because previous research has shown little variation in these physical activity components among middle-aged women ${ }^{(11,15)}$. The PWMAQ includes information on thirty-eight leisure physical activities common among this population subgroup. Leisure physical activity levels were calculated as the product of the duration and frequency of each activity (in h/week), weighted by an estimate of the metabolic equivalent (MET) of that activity ${ }^{(16)}$ and summed for all activities performed. Estimates for total leisure physical activity (all thirty-eight activities) were computed and data are expressed as MET hours per week $(\text { MET } \cdot h / \text { week })^{(3)}$.

In the PAW study, the PWMAQ was administered by a trained interviewer. During the interview, a calendar was placed near the participant so that she could use it to refer back the actual days that made up the recall time frame. This technique was incorporated to assist recall and improve the precision of the computed estimates. Participants were asked whether they had participated in any of the thirty-eight leisure physical activities for at least $10 \mathrm{~min}$ at a time during the previous $7 \mathrm{~d}$. If the participant responded in the affirmative, the interviewer went through each day, one by one, and information regarding the duration of the activity on each of the seven days was queried. Since the PWMAQ utilizes a past-week recall which may not reflect usual physical activity levels due to acute changes in health status, seasonal variation or other causes of short-term variability in physical activity, a question was added to examine the degree to which the summary estimates were influenced by these issues. This question was phrased as: 'Was this week reflective of your usual physical activity levels?' Following survey administration, the interviewer checked a box that 
best reflected the months that the physical activity data were collected (i.e. June to August, September to November, December to February, or March to May). This question was added to the PWMAQ so that summary estimates could be adjusted for the possible influence of seasonality. In the PAW study, the PWMAQ was administered twice during weeks 3 and 4 of the 6-week study and the test-retest reliability of the physical activity and inactivity summary estimates were established over a 1-week interval.

\section{Objective measures of physical activity}

Objective physical activity data were collected using the ActiGraph GT1M accelerometer (Pensacola, FL, USA). The ActiGraph is a small $(3.8 \mathrm{~cm} \times 3.7 \mathrm{~cm} \times 1.8 \mathrm{~cm})$, uniaxial piezoelectric accelerometer, typically worn at the waist, which measures acceleration in the vertical plane. Data output from the ActiGraph accelerometer are activity counts, which quantify the amplitude and frequency of detected accelerations. Activity counts are summed over a user-specified time interval (i.e. epoch). In the current study, an epoch of $1 \mathrm{~min}$ is reported. The sum of the activity counts in a given epoch is related to activity intensity and can be categorized based on validated activity count cut-off points ${ }^{(17)}$. Technical specifications, as well as reliability and validity of the ActiGraph ${ }^{(17,18)}$, have been described previously.

Participants wore the ActiGraph (dominant hip) every day during the 6-week study and were asked to record the time at which they put on the monitor in the morning and the time they took off the monitor at night in a physical activity diary provided by study staff. At the end of each week, the participant returned the physical activity diary to study staff and was given another diary to complete during the following week. Data from the accelerometer were downloaded and processed weekly. Data from the accelerometer were downloaded and screened for wear time using methods consistent with publicly available SAS code developed to process the 2003-2004 National Health and Nutrition Examination Survey $^{(19)}$. Each day, a minimum of $10 \mathrm{~h}$ of wear time was required for data to be considered for further use in calculating accelerometer-determined variables. Average total activity counts per day were calculated using summed daily counts detected over wear periods as a measure of physical activity volume. Time (i.e. minutes) spent in moderate- and vigorous-intensity physical activity was estimated using Freedson et al.'s ${ }^{(20)}$ cut-off points and moderate-lifestyle-intensity activities were estimated using cut-off points proposed by Matthews ${ }^{(17)}$. Resulting count ranges for activity of light (100-759 counts/min), moderate-lifestyle (760-1951 counts/min), moderatewalk (1952-5724 counts/min) and vigorous ( $\geq 5725$ counts/min) intensity were computed for each day with $\geq 10 \mathrm{~h}$ of wear time. Two distinct MVPA categories were computed: lifestyle-MVPA and walk-MVPA ${ }^{(1,17,20)}$. Data were also summarized using methods described by Troiano et $a l^{(2)}$ as bouted physical activity and were defined as ten or more consecutive minutes above a relative cut-off point, with allowance for interruptions of 1-2 min below a cut-off point (referred to as a 'modified activity bout'). Mean times spent in lifestyle-MVPA, walk-MVPA and vigorous-intensity modified activity bouts were calculated. To examine the validity of the TV watching/non-occupational computer use question, categories of physical inactivity $(<100$ counts/min) and the proportion of physical inactivity to total wear time were also computed. Weekly summary accelerometerdetermined physical activity estimates were compiled for all participants with at least four valid days of $10 \mathrm{~h}$ or more of wear time.

\section{Potential confounding factors}

Age (years) and demographics including race/ethnicity, educational attainment and health behaviour information (i.e. smoking status) were collected using a standardized questionnaire. Regarding anthropometric measures, height (m) and weight $(\mathrm{kg})$ were measured with a stadiometer and calibrated balance beam scale, respectively, from which BMI $\left(\mathrm{kg} / \mathrm{m}^{2}\right)$ was calculated.

\section{Statistical methods}

Univariate analyses were conducted on measured parameters including demographics, anthropometric measures, and physical activity and inactivity levels. All variables were assessed for normality. Normally distributed variables are reported as mean and standard deviation, non-normally distributed variables as median with interquartile range (IQR), and proportions are noted for categorical variables. The test-retest reliability of the physical inactivity summary estimates was evaluated using the intra-class correlation coefficient (ICC). The strength of agreement for the ICC ranges were interpreted as follows: $<0 \cdot 00$, poor; $0 \cdot 00-0 \cdot 20$, slight; $0 \cdot 21-0 \cdot 40$, fair; $0 \cdot 41-0 \cdot 60$, moderate; $0 \cdot 61-0 \cdot 80$, substantial; and $0 \cdot 81-$ $1 \cdot 00$, almost perfect ${ }^{(21)}$. Spearman rank-order correlation coefficients were used to determine the association between the total leisure physical activity estimate from the first administration of the PWMAQ and accelerometerdetermined data. Partial correlations were used to further explore whether the results warranted further adjustment by age and BMI. All correlations between the physical activity questionnaires and objective physical activity measures were based on: (i) comparable reporting and data collection intervals for data accumulated as modified bouts; and (ii) accelerometer data averaged over the duration of the study (i.e. 5 weeks) for all data to provide a measure of usual activity. ICC were estimated using the SPSS statistical software package version 15.0 (SPSS Inc., Chicago, IL, USA) and all remaining statistical analyses were conducted using the SAS statistical software package version 9·1 (SAS Institute, Cary, NC, USA). 


\section{Results}

\section{Descriptive statistics}

The mean age of participants was 52.6 (SD 5.4) years; most were non-Hispanic white, college-educated and non-smokers (Table 1). Median total leisure physical activity levels obtained from the first and second administration of the PWMAQ were similar, $21 \cdot 5$ (IQR 8.6, 34.9) and $22 \cdot 4$ (IQR 9.9, 36.3) MET·h/week, respectively ${ }^{(1)}$. Participants also reported the same amount of time spent watching TV or non-occupational computer use on each administration of the survey, i.e. median $2 \cdot 0$ (IQR $1 \cdot 0$, $3 \cdot 0) \mathrm{h} /$ week. During the first administration of the survey, $54.6 \%$ of study participants indicated that their reported physical activity was reflective of usual physical activity participation; $67 \cdot 7 \%$ responded in this manner during the second administration. Regarding questions that pertain to extreme levels of inactivity due to disability, $3 \cdot 0 \%$ of PAW study participants reported being confined to a bed or chair as a result of injury, illness or surgery on at least one of $7 \mathrm{~d}$ during week $3 ; 6 \cdot 2 \%$ reported at least one day of bed or chair rest during week 4 . Only one participant (1.5\%) reported difficulty getting into or out of a bed or chair during the first administration of the survey.

In the current report, descriptive accelerometer data are presented two ways: every minute above a specified cut-off point (i.e. temporally matched) and accumulated in modified activity bouts lasting at least 8 min in duration (i.e. temporally matched and averaged over 5 weeks) (Table 2). Averaged accelerometer data presented as every minute within ActiGraph cut-off points have been reported previously ${ }^{(1)}$. Based on these data, PAW study participants were active, but on average did not meet the 2008 Physical Activity Guidelines for Americans, which recommend at least $150 \mathrm{~min}$ of moderate-intensity physical activity per week ${ }^{(22)}$.

\section{Reliability}

The reproducibility of the total leisure physical activity estimate from the PWMAQ has been reported before ${ }^{(1)}$. The test-retest reliability of the TV watching/nonoccupational computer use question was ICC $=0.77(95 \%$ CI $0.57,0 \cdot 82 ; P<0 \cdot 0001)$, which suggests substantial reproducibility.

\section{Validity}

The relationship between the total leisure physical activity estimate from the first administration of the PWMAQ and temporally matched accelerometer data that included every minute within intensity cut-off point thresholds has been previously reported ${ }^{(1)}$. The PWMAQ leisure physical activity estimate was significantly related to average accelerometer counts per minute per day (counts/min per d) and time spent per day $(\mathrm{min} / \mathrm{d})$ in moderate-lifestyle-, moderate-walk- and vigorous-intensity physical activity (all $P<0.05$; Table 3 ). The total leisure physical activity estimate from the PWMAQ was also significantly related to time spent $(\mathrm{min} / \mathrm{d})$ in lifestyle- and walk-MVPA (both $P<0 \cdot 0001$ ), as well as bouts of lifestyle- and walk-MVPA and vigorous-intensity physical activity (all $P<0 \cdot 001$ ). In general, when compared with temporarily matched accelerometer data, averaged accelerometer data elicited

Table 1 Descriptive characteristics of study participants: the Evaluation of Physical Activity Measures in Middle-Aged Women (PAW) study

\begin{tabular}{|c|c|c|c|c|c|c|}
\hline & \multicolumn{3}{|c|}{ Visit 1} & & & \\
\hline & $n$ & Mean or \% & SD & & & \\
\hline Age (years) & 66 & $52 \cdot 6$ & $5 \cdot 4$ & & & \\
\hline BMI $\left(\mathrm{kg} / \mathrm{m}^{2}\right)$ & 66 & $26 \cdot 8$ & $5 \cdot 1$ & & & \\
\hline White (\%) & 66 & $81 \cdot 8$ & - & & & \\
\hline$\geq 4$-Year college degree (\%) & 66 & $51 \cdot 5$ & - & & & \\
\hline \multirow[t]{2}{*}{ Current smoker (\%) } & 66 & $9 \cdot 1$ & - & & & \\
\hline & \multicolumn{3}{|c|}{ Visit 3} & \multicolumn{3}{|c|}{ Visit 4} \\
\hline Past-week Modifiable Activity Questionnaire & $n$ & Median or $\%$ & IQR & $n$ & Median or $\%$ & IQR \\
\hline \multicolumn{7}{|l|}{ Inactivity } \\
\hline TV watching/non-occupational computer use (h/week) & 66 & $2 \cdot 0$ & $1 \cdot 0,3 \cdot 0$ & 65 & $2 \cdot 0$ & $1 \cdot 0,3 \cdot 0$ \\
\hline Reported data reflective of usual leisure PA? (\% yes) & 66 & $54 \cdot 6$ & - & 65 & $67 \cdot 7$ & - \\
\hline $\begin{array}{l}\text { Confined to a bed or chair as a result of injury, illness } \\
\text { or surgery? (\% yes) }\end{array}$ & 66 & $3 \cdot 0$ & - & 65 & $6 \cdot 2$ & - \\
\hline Difficulty getting into or out of a bed or chair? (\% yes) & 66 & $1 \cdot 5$ & - & 65 & $0 \cdot 0$ & - \\
\hline Difficulty walking across a small room without resting? (\% yes) & 66 & $0 \cdot 0$ & - & 65 & $0 \cdot 0$ & - \\
\hline Difficulty walking for $10 \mathrm{~min}$ without resting? (\% yes) & 66 & $0 \cdot 0$ & - & 65 & $0 \cdot 0$ & - \\
\hline Season of data collection & 66 & & & 65 & & \\
\hline June-August (\%) & & 1.5 & - & & $0 \cdot 0$ & - \\
\hline September-November (\%) & & $39 \cdot 4$ & - & & $35 \cdot 4$ & - \\
\hline December-February (\%) & & $31 \cdot 8$ & - & & $29 \cdot 2$ & - \\
\hline March-May (\%) & & $27 \cdot 3$ & - & & $35 \cdot 4$ & - \\
\hline
\end{tabular}

TV, television; PA, physical activity; IQR, interquartile range.

Normally distributed variables are reported as mean and standard deviation; non-normally distributed variables are reported as median and interquartile range; proportions are noted for categorical variables. 
Table 2 Accelerometer-determined data during weeks 2-3 and averaged over 5 weeks in study participants $(n$ 64): the Evaluation of Physical Activity Measures in Middle-Aged Women (PAW) study

\begin{tabular}{|c|c|c|c|c|}
\hline & \multicolumn{2}{|c|}{ Time-matched } & \multicolumn{2}{|c|}{ 5-Week average } \\
\hline & Median or mean & SD or IQR & Median or mean & SD or IQR \\
\hline \multicolumn{5}{|l|}{ Every minute within ActiGraph cut-off points } \\
\hline Average wear time $(\mathrm{min} / \mathrm{d})$ & $870 \cdot 6$ & $810 \cdot 8,912 \cdot 2$ & $864 \cdot 8$ & $823 \cdot 2,909 \cdot 8$ \\
\hline Average counts (countst/min per d) & $305 \cdot 2$ & $219 \cdot 9,385 \cdot 5$ & $297 \cdot 5 \ddagger$ & $235 \cdot 2,358 \cdot 7$ \\
\hline Physical inactivity (0-99 counts) (min/d) & $538 \cdot 7$ & $73 \cdot 8$ & $538 \cdot 3$ & $63 \cdot 0$ \\
\hline Physical inactivity/average wear timet & $0 \cdot 62$ & 0.07 & 0.63 & 0.07 \\
\hline Light-intensity PA (100-759 counts) (min/d) & $214 \cdot 1$ & $194 \cdot 3,257 \cdot 4$ & $217 \cdot 6 \ddagger$ & $187 \cdot 9,256 \cdot 9$ \\
\hline Moderate-lifestyle-intensity PA (760-1951 counts) (min/d) & $66 \cdot 3$ & $49 \cdot 8,81 \cdot 7$ & $66 \cdot 0 \ddagger$ & $51 \cdot 2,81 \cdot 3$ \\
\hline Moderate-walk-intensity PA (1952-5724 counts) ( $\mathrm{min} / \mathrm{d})$ & $25 \cdot 1$ & $13 \cdot 5,38 \cdot 6$ & $23 \cdot 1 \ddagger$ & $14 \cdot 1,34 \cdot 6$ \\
\hline Vigorous-intensity PA ( $\geq 5725$ counts) $(\mathrm{min} / \mathrm{d})$ & $0 \cdot 1$ & $0 \cdot 0,3 \cdot 5$ & $0 \cdot 4 \ddagger$ & $0 \cdot 0,2 \cdot 3$ \\
\hline Moderate-lifestyle- to vigorous-intensity PA ( $\geq 760$ counts) $(\mathrm{min} / \mathrm{d})$ & $96 \cdot 7$ & $70 \cdot 3,118 \cdot 0$ & $100 \cdot 3 \ddagger$ & $74 \cdot 4,113 \cdot 9$ \\
\hline Moderate-walk- to vigorous-intensity PA ( $\geq 952$ counts) $(\mathrm{min} / \mathrm{d})$ & $26 \cdot 1$ & $14 \cdot 2,43 \cdot 7$ & $24 \cdot 3 \ddagger$ & $15 \cdot 9,41 \cdot 6$ \\
\hline \multicolumn{5}{|l|}{ Modified activity bouts } \\
\hline Moderate-lifestyle- to vigorous-intensity PA ( $\geq 760$ counts) $(\mathrm{min} / \mathrm{d})$ & $32 \cdot 7$ & $16 \cdot 6,58 \cdot 3$ & $33 \cdot 6$ & $18 \cdot 2,54 \cdot 6$ \\
\hline Moderate-walk- to vigorous-intensity PA ( $\geq 1952$ counts) (min/d) & $13 \cdot 3$ & $3 \cdot 8,23 \cdot 7$ & $11 \cdot 3$ & $5 \cdot 2,19 \cdot 2$ \\
\hline Vigorous-intensity PA ( $\geq 5725$ counts) $(\mathrm{min} / \mathrm{d})$ & $0 \cdot 0$ & $0.0,1.9$ & $0 \cdot 0$ & $0 \cdot 0,2 \cdot 0$ \\
\hline
\end{tabular}

IQR, interquartile range; PA, physical activity.

Data are reported as median and interquartile range or mean and standard deviation.

tCalculated as physical inactivity $(\mathrm{min} / \mathrm{d})$ divided by average wear time $(\mathrm{min} / \mathrm{d})$.

$\ddagger$ Results published previously in Pettee Gabriel et al. ${ }^{(1)}$.

Table 3 Spearman rank-order correlation coefficients between the first administration of the past-week Modifiable Activity Questionnaire (PWMAQ) and accelerometer-determined data (time-matched to fit the recall time frame and 5-week average) in the study participants ( $n$ 64): the Evaluation of Physical Activity Measures in Middle-Aged Women (PAW) study

\begin{tabular}{|c|c|c|c|c|}
\hline & \multicolumn{4}{|c|}{ PWMAQ leisure PA (MET.h/week) } \\
\hline & \multicolumn{2}{|c|}{ Unadjusted } & \multicolumn{2}{|c|}{ Adjusted for age and BMI } \\
\hline & $\begin{array}{c}\text { Time- } \\
\text { matched }\end{array}$ & $\begin{array}{l}5 \text {-Week } \\
\text { average }\end{array}$ & $\begin{array}{c}\text { Time- } \\
\text { matched }\end{array}$ & $\begin{array}{l}\text { 5-Week } \\
\text { average }\end{array}$ \\
\hline \multicolumn{5}{|l|}{ Every minute within ActiGraph cut-off points } \\
\hline Average counts (counts/min per $\mathrm{d}$ ) & $0 \cdot 56^{\star \star \star \star}+$ & $0 \cdot 69^{\star \star \star *}$ & $0 \cdot 49^{\star \star \star}+$ & $0 \cdot 63^{\star \star \star \star}$ \\
\hline Light-intensity PA (100-759 counts) (min/d) & $0 \cdot 06 t$ & $0 \cdot 15$ & $0 \cdot 002 t$ & $0 \cdot 16$ \\
\hline Moderate-lifestyle-intensity PA (760-1951 counts) (min/d) & $0 \cdot 25^{\star} \dagger$ & $0 \cdot 33^{\star \star}$ & $0 \cdot 25 t$ & $0 \cdot 37^{\star \star}$ \\
\hline Moderate-walk-intensity PA (1952-5724 counts) (min/d) & $0.58^{\star \star \star \star} \dagger$ & $0 \cdot 66^{\star \star \star \star}$ & $0.52^{\star \star \star \star} \dagger$ & $0 \cdot 61^{\star \star \star \star}$ \\
\hline Vigorous-intensity PA ( $\geq 5725$ counts) $(\mathrm{min} / \mathrm{d})$ & $0 \cdot 44^{\star \star \star}+$ & $0 \cdot 46^{\star \star \star \star}$ & $0 \cdot 42^{\star \star}+$ & $0 \cdot 36^{\star \star}$ \\
\hline Moderate-lifestyle- to vigorous-intensity PA ( $\geq 760$ counts) (min/d) & $0.52^{\star \star \star \star} \dagger$ & $0 \cdot 67^{\star \star \star \star}$ & $0.54^{\star * \star *} \dagger$ & $0 \cdot 64^{\star \star \star \star}$ \\
\hline Moderate-walk- to vigorous-intensity PA ( $\geq 1952$ counts) (min/d) & $0 \cdot 60^{\star \star \star \star} \dagger$ & $0 \cdot 66^{\star \star \star \star}$ & $0 \cdot 48^{\star \star \star} \dagger$ & $0 \cdot 60^{\star \star \star *}$ \\
\hline \multicolumn{5}{|l|}{ Modified activity bouts } \\
\hline Moderate-lifestyle- to vigorous-intensity PA ( $\geq 760$ counts) (min/d) & $0 \cdot 72^{\star \star \star \star}$ & $0 \cdot 76^{\star \star \star \star}$ & $0 \cdot 67^{\star \star \star \star}$ & $0 \cdot 73^{\star \star \star \star}$ \\
\hline Moderate-walk- to vigorous-intensity PA ( $\geq 1952$ counts) (min/d) & $0 \cdot 59^{* \star \star *}$ & $0 \cdot 69^{\star \star \star *}$ & $0 \cdot 53^{\star \star \star \star}$ & $0 \cdot 63^{\star \star \star *}$ \\
\hline Vigorous-intensity PA ( $\geq 5725$ counts) $(\mathrm{min} / \mathrm{d})$ & $0 \cdot 43^{\star \star \star}$ & $0 \cdot 41^{\star \star \star}$ & $0 \cdot 38^{\star \star}$ & $0 \cdot 35^{\star \star}$ \\
\hline
\end{tabular}

PA, physical activity; MET, metabolic equivalent.

Correlation was statistically significant: ${ }^{\star} P<0 \cdot 05,{ }^{\star \star} P<0.01,{ }^{\star \star \star} P<0.001,{ }^{\star \star \star \star} P<0.0001$

tResults published previously in Pettee Gabriel et al. ${ }^{(1)}$.

higher correlations with the PWMAQ. When the correlations were adjusted for age and BMI, the findings were similar (Table 3). Reported time spent watching TV/nonoccupational computer use was not significantly related to time-matched $(\rho:-0 \cdot 21$ to 0.08 (moderate-walk- and light-intensity physical activity, respectively); all $P>0 \cdot 05$ ) or averaged accelerometer-determined estimates of physical inactivity or activity $(\rho:-0 \cdot 13$ to $0 \cdot 10$ (walk-MVPA and light-intensity physical activity, respectively); all $P>0 \cdot 05$ ). Additional adjustment for age and BMI did not elicit strikingly different findings.

Total leisure physical activity was significantly related to time spent in moderate-walk- and vigorous-intensity physical activity regardless of whether reported data were indicative of usual physical activity levels; however, the relationship with vigorous-intensity activity was statistically significant only in those who indicated that reported activity was reflective of usual physical activity levels ( $\rho: 0.53 v .0 .18$ and $0.45 v .0 .18$ for temporally matched and averaged accelerometer data, respectively; Table 4). In contrast, the relationship between the PWMAQ physical activity estimate and moderate-lifestyle-intensity activity was higher in those reporting that the reported data were not reflective of their usual physical activity levels $(\rho: 0.02 \quad v .0 .47$ and $0.14 \quad v .0 .3$ for temporally matched and averaged accelerometer data, respectively). 
Table 4 Unadjusted and adjusted Spearman rank-order correlation coefficientst between the first administration of the past-week Modifiable Activity Questionnaire (PWMAQ) and accelerometer-determined data, stratified by participants reporting that the week recalled was reflective or not reflective of usual physical activity levels: the Evaluation of Physical Activity Measures in Middle-Aged Women (PAW) study

\begin{tabular}{|c|c|c|c|c|}
\hline & \multicolumn{4}{|c|}{ PWMAQ leisure PA (MET·h/week) } \\
\hline & \multicolumn{2}{|c|}{ Time-matched } & \multicolumn{2}{|c|}{ 5-Week average } \\
\hline & $\begin{array}{c}\text { Not reflective } \\
\quad(n 29)\end{array}$ & $\begin{array}{l}\text { Reflective } \\
\quad(n 35)\end{array}$ & $\begin{array}{l}\text { Not reflective } \\
\quad(n \text { 29) }\end{array}$ & $\begin{array}{l}\text { Reflective } \\
\quad(n \text { 35) }\end{array}$ \\
\hline \multicolumn{5}{|l|}{ UNADJUSTED } \\
\hline \multicolumn{5}{|l|}{ Every minute within ActiGraph cut-off points } \\
\hline Average counts (counts/min per d) & $0 \cdot 48^{\star \star}$ & $0 \cdot 65^{\star \star \star \star}$ & $0 \cdot 58^{\star \star \star}$ & $0 \cdot 66^{\star \star \star \star}$ \\
\hline Light-intensity PA (100-759 counts) (min/d) & $0 \cdot 12$ & $-0 \cdot 19$ & $0 \cdot 23$ & $-0 \cdot 19$ \\
\hline Moderate-lifestyle-intensity PA (760-1951 counts) ( $\min / \mathrm{d})$ & $0 \cdot 47^{\star \star}$ & 0.02 & $0.53^{\star *}$ & 0.14 \\
\hline Moderate-walk-intensity PA (1952-5724 counts) (min/d) & $0 \cdot 47^{\star \star}$ & $0 \cdot 68^{\star * \star *}$ & $0 \cdot 51^{\star *}$ & $0 \cdot 68^{\star \star \star *}$ \\
\hline Vigorous-intensity PA ( $\geq 5724$ counts) $(\mathrm{min} / \mathrm{d})$ & $0 \cdot 18$ & $0 \cdot 53^{\star \star \star}$ & $0 \cdot 18$ & $0 \cdot 45^{\star \star}$ \\
\hline Moderate-lifestyle- to vigorous-intensity PA ( $\geq 760$ counts) $(\mathrm{min} / \mathrm{d})$ & $0 \cdot 57^{\star \star \star}$ & $0.45^{\star \star}$ & $0 \cdot 65^{\star \star \star \star}$ & $0.54^{\star \star \star}$ \\
\hline Moderate-walk- to vigorous-intensity PA ( $\geq 1952$ counts) $(\mathrm{min} / \mathrm{d})$ & $0 \cdot 47^{\star \star}$ & $0 \cdot 69^{* \star \star \star}$ & $0 \cdot 51^{\star \star}$ & $0 \cdot 68^{\star \star \star \star}$ \\
\hline \multicolumn{5}{|l|}{ Modified activity bouts } \\
\hline Moderate-lifestyle- to vigorous-intensity PA ( $\geq 760$ counts) (min/d) & $0 \cdot 72^{\star \star \star \star}$ & $0 \cdot 79^{\star \star \star *}$ & $0 \cdot 77^{\star \star \star *}$ & $0 \cdot 78^{* \star \star *}$ \\
\hline Moderate-walk- to vigorous-intensity PA ( $\geq 1952$ counts) (min/d) & $0 \cdot 41^{\star}$ & $0 \cdot 71^{\star \star \star \star}$ & $0 \cdot 39^{*}$ & $0 \cdot 70^{\star \star \star \star}$ \\
\hline Vigorous-intensity PA ( $\geq 5725$ counts) $(\mathrm{min} / \mathrm{d})$ & $0 \cdot 18^{*}$ & $0 \cdot 51^{* *}$ & $0 \cdot 21$ & $0 \cdot 44^{\star \star}$ \\
\hline \multicolumn{5}{|l|}{ ADJUSTED $\ddagger$} \\
\hline \multicolumn{5}{|l|}{ Every minute within ActiGraph cut-off points } \\
\hline Average counts (counts/min per d) & $0.43^{*}$ & $0 \cdot 58^{\star * \star}$ & $0 \cdot 58^{\star * \star}$ & $0 \cdot 66^{\star \star \star *}$ \\
\hline Light-intensity PA (100-759 counts) (min/d) & 0.04 & $-0 \cdot 16$ & $0 \cdot 23$ & $-0 \cdot 19$ \\
\hline Moderate-lifestyle-intensity PA (760-1951 counts) (min/d) & $0 \cdot 44^{\star}$ & 0.08 & $0.53^{\star *}$ & $0 \cdot 14$ \\
\hline Moderate-walk-intensity PA (1952-5724 counts) (min/d) & $0 \cdot 42^{*}$ & $0 \cdot 61^{\star \star \star}$ & $0.51^{* *}$ & $0 \cdot 68^{\star \star \star \star}$ \\
\hline Vigorous-intensity PA ( $\geq 5724$ counts) $(\mathrm{min} / \mathrm{d})$ & $0 \cdot 19$ & $0 \cdot 44^{*}$ & $0 \cdot 18$ & $0 \cdot 45^{\star \star}$ \\
\hline Moderate-lifestyle- to vigorous-intensity PA ( $\geq 760$ counts) ( $\mathrm{min} / \mathrm{d})$ & $0.53^{\star *}$ & $0 \cdot 41^{*}$ & $0.65^{\star \star \star \star}$ & $0 \cdot 54^{\star \star \star}$ \\
\hline Moderate-walk- to vigorous-intensity PA ( $\geq 1952$ counts) $(\mathrm{min} / \mathrm{d})$ & $0 \cdot 43^{*}$ & $0.62^{\star * \star *}$ & $0.51^{\star *}$ & $0.69^{\star \star \star \star}$ \\
\hline \multicolumn{5}{|l|}{ Modified activity bouts } \\
\hline Moderate-lifestyle- to vigorous-intensity PA ( $\geq 760$ counts) (min/d) & $0.69^{\star \star \star *}$ & $0 \cdot 74^{\star \star \star *}$ & $0 \cdot 77^{\star \star \star \star}$ & $0 \cdot 68^{\star \star \star \star}$ \\
\hline Moderate-walk- to vigorous-intensity PA ( $\geq 1952$ counts) (min/d) & $0 \cdot 38^{*}$ & $0 \cdot 65^{\star \star \star \star}$ & $0 \cdot 39^{*}$ & $0 \cdot 70^{\star \star \star \star}$ \\
\hline Vigorous-intensity PA ( $\geq 5725$ counts) $(\mathrm{min} / \mathrm{d})$ & $0 \cdot 20^{*}$ & $0 \cdot 44^{*}$ & $0 \cdot 21$ & $0 \cdot 44^{\star \star}$ \\
\hline
\end{tabular}

PA, physical activity; MET, metabolic equivalent.

Correlation was statistically significant: ${ }^{\star} P<0.05,{ }^{\star \star} P<0.01,{ }^{\star \star \star} P<0.001,{ }^{\star \star \star \star} P<0.0001$.

tCorrelation coefficients were generated using Fisher's $Z$ transformation to account for difference in sample size between not reflective $v$. reflective of usual activity.

$\ddagger$ Adjusted for age (years) and BMl $\left(\mathrm{kg} / \mathrm{m}^{2}\right)$.

The stratified results also suggest that estimated total leisure physical activity was significantly related to lifestyle- and walk-MVPA; regardless of whether accelerometer data were computed to include every minute above a cut-off point or in modified activity bouts (all $P<0 \cdot 05$ ). However, correlations with walk-MVPA were higher in women who reported that their physical activity was reflective of usual behaviour. Similar results were obtained when correlations were further adjusted for age and BMI.

\section{Discussion}

In the current investigation the test-retest reliability of the physical inactivity estimate and validity of the leisure physical activity and inactivity estimates computed from the PWMAQ were examined. Findings suggest that although the physical inactivity estimates were reliable, only leisure physical activity was significantly related to accelerometerdetermined data. However, when interpreting these results it is important to note that the PWMAQ queries active and sedentary leisure activities only, whereas the accelerometer records activity counts that are accumulated throughout the entire day. This is a potential source of error in most validation studies that include activity monitors as the criterion measure for comparison. That being said, this may have contributed to the non-significant association that was observed between the TV watching/non-occupational computer use question and accelerometer-derived data and is suggestive of the inability of the accelerometer to differentiate alternative forms of sedentary behaviour from TV watching or computer use. Further, the lack of association could have also been the result of the low number of reported hours that were spent participating in these sedentary activities or the limited variability of the PWMAQ physical inactivity estimate across PAW study participants, which may be suggestive of social desirability bias.

As previously reported ${ }^{(1)}$, the PWMAQ total leisure physical activity estimate was significantly related to temporally matched raw (i.e. total counts per day) and derived moderate- to vigorous-intensity accelerometer-determined physical activity. The current study expands upon these findings by presenting additional comparisons with MVPA and vigorous-intensity activity accumulated as modified 
activity bouts. Further, differences in obtained correlation coefficients between PWMAQ and temporally matched and averaged accelerometer-derived estimates were evaluated. More specifically, in the current study significant relationships were observed with accelerometer-derived data regardless of whether the intensity-specific estimates included every minute within a cut-off point threshold or were accumulated as part of a modified activity bout. However, correlations between the leisure physical activity estimate and averaged accelerometer data were higher than with data that fit the recall time frame of the questionnaire. This finding was particularly interesting given the fact that a calendar was made available to the participants during the interview to enhance recall of physical activity and inactivity and frequent reminders regarding the specific dates for recall were provided by the interviewer to assist recall. The higher correlations that were observed with the accelerometer data averaged over the study duration may support theories regarding the cognitive processes by which individuals encode, store and retrieve physical activity information from the autobiographical memory ${ }^{(23,24)}$.

After adjustment for age and BMI, the higher correlations that were observed with averaged accelerometer data, rather than temporally matched data, held true for all intensity levels except for vigorous-intensity physical activity. One possible explanation for this finding relates to the notion that individuals are most accurate when reporting never participating in a particular behaviour $^{(25,26)}$. The low levels of vigorous-intensity physical activity derived from the accelerometer suggest that participation in the higher-intensity physical activities was not common among PAW study participants. Although $72.7 \%$ ( $n$ 48) of PAW study participants recorded some vigorous-intensity physical activity minutes on the accelerometer, the median time spent in vigorous-intensity activities was less than $2 \mathrm{~min} /$ week. Therefore, the task of accurately recalling no participation in vigorous-intensity activities via self-report may have been less cognitively challenging for participants. Also, in general, individuals are better able to provide accurate estimates of time spent in vigorous-intensity physical activities because these activities tend to be more structured in nature, occur less frequently, and are often stored with contextual information (e.g. locations, people or social occasions) that can be used to aid recall. The improved accuracy with self-report of higher-intensity physical activities within a given time frame that was observed in the current report supports previous research efforts in this area ${ }^{(25,27)}$. More studies are needed that focus on cognitive aspects of the recall of physical activity.

In the current report, the correlations between the leisure estimate from the PWMAQ and accumulated minutes spent in moderate-lifestyle-intensity physical activity were moderate to weak (adjusted $\rho=0.25$ and 0.37 for time-matched and averaged accelerometer data, respectively). The PWMAQ consists of leisure activities that require $\geq 3$ MET, defined as moderate- and vigorousintensity physical activity. Therefore, the weak correlations that were observed with light- and moderate-lifestyleintensity physical activity support the goal of the PWMAQ to assess only moderate- and vigorous-intensity physical activities and filter out participation in lower-intensity activities. Further, during the interview participants were asked to report activities that they participated in for at least $10 \mathrm{~min}$ at a time. The higher correlations that were observed between the total leisure physical activity estimate and accelerometer data that occurred as part of a modified activity bout also support compliance to the instructions given by the interviewer prior to survey administration.

The current study also expands upon the previous evaluation study of the PWMAQ ${ }^{(1)}$ by evaluating the practicality and usefulness of an additional question asking respondents to indicate whether the reported physical activity data reflected usual behaviour. With the exception of moderate-lifestyle-intensity physical activity, the strength of the associations that were observed between the leisure physical activity estimate and accelerometer-derived data was maximized among participants who stated that the data reported were reflective of their usual physical activity levels and supports the utility of this question. Again, given the associated MET value and structured nature of the activities included in the PWMAQ, this finding is not particularly surprising. In practical application, we recommend that researchers use this question to stratify the study population in order to more closely evaluate to what extent issues of seasonality or changes in health status impact the PWMAQ total leisure physical activity estimate.

Several limitations need to be considered when interpreting the study results. It is possible that establishing reliability over a relatively short interval may be influenced by a learning effect. Further, PAW study participants were composed of a convenience sample of healthy, highly educated, relatively active, non-Hispanic white women, which may limit the generalizability of the findings to a more diverse group of middle-aged women. Finally, the use of an accelerometer to validate physical activity questionnaires is limited in that waist-worn, uniaxial accelerometers are less accurate when assessing non-ambulatory (i.e. cycling, weight-lifting) and water activities (i.e. swimming, water aerobics) ${ }^{(28)}$.

The current study provides an in-depth evaluation of the test-retest reliability and convergent validity of the PWMAQ in healthy, middle-aged women. Physical inactivity summary estimates from the PWMAQ were deemed reliable over one week and the leisure physical activity estimate was validated against a multitude of accelerometer summary scores. Further, results from the current report support the use of a simple, one-item question that examines whether self-reported physical activity was reflective of usual activity. Given the increasing interest in 
examining the role of physical activity on mortality and health outcomes in women, the present results support the utility of the PWMAQ to provide a reliable and valid estimate of leisure physical activity levels among middleaged women. Further, these results support future efforts designed to evaluate this physical activity level in other adult population subgroups.

\section{Acknowledgements}

Sources of funding: This work was supported by the American College of Sports Medicine, Paffenbarger-Blair Endowment for Epidemiological Research on Physical Activity that was awarded to K.P.G. while working as a post-doctoral research associate at Arizona State University. The results of the present study do not constitute endorsement by the American College of Sports Medicine. Conflict of interest declaration: The authors are not aware of any conflict of interest related to any aspect of the research or report nor have any arrangements related to the content of the paper or the research. The manuscript has not been published elsewhere, nor is the paper under consideration for publication elsewhere. Author contributions: All authors have participated in the research reported and all have agreed to be an author on the paper. K.P.G. was a significant writer, was involved in the study concept/design, data acquisition and data analysis. J.J.M. was a significant reviewer and was involved in the data acquisition. K.K.S. was a significant reviewer and provided statistical expertise. K.L.S. was a significant reviewer and was involved in the concept/design of the study. B.E.A. was a significant reviewer and was involved in the concept/design of the study. Acknowledgements: The authors would like to acknowledge the sixty-six dedicated PAW study participants and the contributions of Melanie Mitros, Rebecca Rankin and Justin Leonard.

\section{References}

1. Pettee Gabriel KK, McClain JJ, Lee CD et al. (2009) The evaluation of physical activity measures used in middleaged women. Med Sci Sports Exerc 41, 1403-1412.

2. Troiano RP, Berrigan D, Dodd KW et al. (2008) Physical activity in the United States measured by accelerometer. Med Sci Sports Exerc 40, 181-188.

3. Kriska AM, Knowler WC, LaPorte RE et al. (1990) Development of questionnaire to examine relationship of physical activity and diabetes in Pima Indians. Diabetes Care 13, 401-411.

4. Kriska AM (1997) Modifiable Activity Questionnaire. Med Sci Sports Exerc 29, 6 Suppl., S73-S78.

5. Kuller LH, Kinzel LS, Pettee KK et al. (2006) Lifestyle intervention and coronary heart disease risk factor changes over 18 months in postmenopausal women: the Women On the Move through Activity and Nutrition (WOMAN Study) clinical trial. J Womens Health 15, 964-976.

6. Vuillemin A, Boini S, Bertrais S et al. (2005) Leisure time physical activity and health-related quality of life. Prev Med 41, 562-569.
7. Riechman SE, Schoen RE, Weissfeld JL et al. (2002) Association of physical activity and visceral adipose tissue in older women and men. Obes Res 10, 1065-1073.

8. Yurgalevitch SM, Kriska AM, Welty TK et al. (1998) Physical activity and lipids and lipoproteins in American Indians ages 45-74. Med Sci Sports Exerc 30, 543-549.

9. Kuller LH, Kriska AM, Kinzel LS et al. (2007) The clinical trial of Women On the Move through Activity and Nutrition (WOMAN) study. Contemp Clin Trials 28, 370-381.

10. Pettee K, Kriska A, Johnson B et al. (2007) The relationship between physical activity and lipoprotein subclasses in postmenopausal women: the influence of hormone therapy. Menopause 14, 115-122.

11. Pettee KK, Kriska AM, Conroy MB et al. (2007) Discontinuing hormone replacement therapy: attenuating the effect on CVD risk with lifestyle changes. Am J Prev Med 32, 483-489.

12. Washburn RA \& Montoye HJ (1986) The assessment of physical activity by questionnaire. Am J Epidemiol 123, 563-576.

13. Trost SG, McIver KL \& Pate RR (2005) Conducting accelerometer-based activity assessments in field-based research. Med Sci Sports Exerc 37, 11 Suppl., S531-S543.

14. Pettee Gabriel KK, Rankin RL, Lee CD et al. (2010) Test-retest reliability and validity of the 400 meter walk test in healthy, middle-aged women. J Phys Act Health 7, 649-657.

15. Newman MA, Pettee KK, Storti KL et al. (2009) Monthly variation in physical activity levels in postmenopausal women. Med Sci Sports Exerc 41, 322-327.

16. Ainsworth BE, Haskell WL, Whitt MC et al. (2000) Compendium of physical activities: an update of activity codes and MET intensities. Med Sci Sports Exerc 32, 9 Suppl., S498-S504.

17. Matthews CE (2005) Calibration of accelerometer output for adults. Med Sci Sports Exerc 37, 11 Suppl., S512-S522.

18. Nichols JF, Morgan CG, Chabot LE et al. (2000) Assessment of physical activity with the Computer Science and Applications, Inc. accelerometer: laboratory versus field validation. Res $Q$ Exerc Sport 71, 36-43.

19. National Cancer Institute (2007) Risk Factor Monitoring and Methods. SAS Programs for Analyzing NHANES 2003-2004 Accelerometer Data. http://riskfactor.cancer. gov/tools/nhanes_pam/ (accessed August 2008).

20. Freedson PS, Melanson E \& Sirard J (1998) Calibration of the Computer Science and Applications, Inc. accelerometer. Med Sci Sports Exerc 30, 777-781.

21. Landis JR \& Koch GG (1977) The measurement of observer agreement for categorical data. Biometrics 33, 159-174.

22. US Department of Health and Human Services (2008) 2008 Physical Activity Guidelines for Americans. http://www. health.gov/paguidelines/ (accessed October 2008).

23. Durante R \& Ainsworth BE (1996) The recall of physical activity: using a cognitive model of the question-answering process. Med Sci Sports Exerc 28, 1282-1291.

24. Baranowski T (1988) Validity and reliability of self report measures of physical activity: an information-processing perspective. Res Q Exerc Sport 59, 314-327.

25. Slattery ML \& Jacobs DR Jr (1995) Assessment of ability to recall physical activity of several years ago. Ann Epidemiol 5, 292-296.

26. Blair SN, Dowda M, Pate RR et al. (1991) Reliability of longterm recall of participation in physical activity by middleaged men and women. Am J Epidemiol 133, 266-275.

27. Sallis JF, Haskell WL, Wood PD et al. (1985) Physical activity assessment methodology in the Five-City Project. Am J Epidemiol 121, 91-106.

28. Troiano RP (2006) Translating accelerometer counts into energy expenditure: advancing the quest. J Appl Physiol 100, 1107-1108. 